\title{
Nasal polyposis, eosinophil dominated inflammation, and allergy
}

\author{
Niels Mygind, Ronald Dahl, Claus Bachert
}

A polyp is an oedematous mucous membrane which forms a pedunculating process with a slim or broad stalk or base. Nasal polyps originate in the upper part of the nose around the openings to the ethmoidal sinuses. The polyps extend into the nasal cavity from the middle meatus, resulting in nasal blockage and restricted airflow to the olfactory region. The polyp stroma is highly oedematous with a varying density of inflammatory cells. Nasal polyposis, consisting of recurrent, multiple polyps, is part of an inflammatory reaction involving the mucous membrane of the nose, paranasal sinuses, and often the lower airways. The polyps are easily accessible for immunological and histological studies and an increasing number of publications have appeared in recent years, including two monographs. ${ }^{12}$

Nasal polyps have long been associated with rhinitis and asthma. However, the role of allergy in the aetiology and pathogenesis of nasal polyps is a controversial issue. It has been postulated that allergy is an aetiological factor for nasal polyposis. If this is so, then it can be expected that allergic patients will have polyps more often than a control population and that patients with polyps have an increased occurrence of positive allergy testing.

In this paper we will describe the possible connection between nasal polyposis and allergy, based on an analysis of (1) the occurrence of polyps and of allergy, (2) the anatomy and histology of nasal polyps, (3) the inflammation in nasal polyps, (4) the occurrence of positive allergy tests in patients with polyps, (5) the effect of allergen exposure on nasal symptoms in patients with polyps, and (6) the response to treatment.

\section{Nasal polyposis with known aetiology}

While the aetiology of nasal polyposis is unknown in many patients, in a few cases it is well defined. Polyps occur in most patients with allergic fungal sinusitis. In this disease the tissue inflammation is typically eosinophil dominated. ${ }^{3}$

Nasal polyps frequently occur in patients with cystic fibrosis and in those with primary ciliary dyskinesia (Kartagener's syndrome). The polyps associated with these diseases are not characterised by tissue eosinophilia but by lymphocytes in the tissue and neutrophil leucocytes in the secretions. ${ }^{4}$

Department of Otorhinolaryngology, University Hospital, Ghent, Belgium

C Bachert

Correspondence to: Dr N Mygind niels.mygind@dadlnet.dk and their results depend upon the diagnostic methods used (history, rhinoscopy, endoscopy,
Occurrence of nasal polyps and of allergy The exact prevalence rate of nasal polyposis in the general population is not known because there have been few epidemiological studies computed tomographic (CT) scanning). The overall prevalence rate is probably about $2-4 \%{ }^{5-7}$ which increases with age of the study population. Nasal polyposis occurs with a high frequency in groups of patients with specified airway diseases (table 1).

Although symptomatic nasal polyposis is rare in the general population, much higher figures for the occurrence of isolated nasal polyps have been obtained from necropsy studies. A thorough endoscopic examination of removed nasoethmoidal blocks and endoscopic examination of unselected necropsy specimens have shown polyps in as many as $25-40 \%$ of specimens. ${ }^{89}$

Allergic rhinitis has a high prevalence rate of about $15-20 \% .^{10}$ Most cases in the western world are caused by pollen allergy, having a seasonal occurrence. In striking contrast to nasal polyposis, which is a disease of middle aged people, allergic rhinitis occurs with its highest prevalence in children and young people and the clinical significance of the diseases decreases with age.

\section{Occurrence of nasal polyps in allergic patients}

Caplin and coworkers ${ }^{11}$ examined 3000 consecutive atopic patients and found that only $0.5 \%$ had polyps. Bunnag and coworkers ${ }^{12}$ reported a $4.5 \%$ incidence of nasal polyps in 300 patients with allergic rhinitis. Settipane and Chaffe ${ }^{13}$ found that only $0.1 \%$ of paediatric patients attending an allergy clinic had nasal polyps. Thus, the prevalence of nasal polyps in allergic patients is low, usually under $5 \%$, which is similar to that of the general population.

Anatomy and histology of nasal polyposis SITE OF POLYP FORMATION

Nasal endoscopic examination of a large number of patients with nasal polyposis ${ }^{14}{ }^{15}$ and a detailed anatomical examination of necropsy specimens ${ }^{89}$ have shown that nasal polyps are

Table 1 Prevalence of nasal polyposis in different population subgroups

$\begin{array}{ll}\text { Aspirin intolerance } & 36-72 \% \\ \text { Adult asthma } & 7 \% \\ \text { IgE mediated } & 5 \% \\ \text { Non-IgE mediated } & 13 \% \\ \text { Chronic sinusitis in adults } & 2 \% \\ \text { IgE mediated } & 1 \% \\ \quad \text { Non-IgE mediated } & 5 \% \\ \text { Childhood asthma/sinusitis } & 0.1 \% \\ \text { Cystic fibrosis } & 10 \% \\ \text { Children } & 50 \% \\ \text { Adults } & 66-100 \% \\ \text { Allergic fungal sinusitis } & 40 \% \\ \text { Primary ciliary dyskinesia } & \end{array}$

Adapted from Settipane et al. ${ }^{1}$ 
mainly situated in the middle meatus and originate from the nasal mucous membrane of the outlets (ostia, clefts, recesses) from the paranasal sinuses. This area, so critical for sinus pathology, is also referred to as "the ostiomeatal complex".

It is remarkable that polyps develop exclusively from a few square centimetres of airway mucous membrane which often is universally inflamed. The reason for this is unknown and one can only speculate about the nature of a "localisation factor". In the upper part of the nose, including the middle meatus, the airway lumen is a narrow slit with only a few millimetres between opposing mucous membranes. Stammberger ${ }^{14} 15$ has observed that polyp formation predominantly occurs in contact areas between two opposing mucous membranes. It is known that stimulation of epithelial cells induces the generation and release of a series of pro-inflammatory cytokines, and one can therefore hypothesise that mechanical stimulation of the surface epithelium in contact areas contributes, or even initiates, the inflammatory reaction in the polyps.

Other "localisation factors" may be related to the anatomy of nerve endings, blood vessels, and mucociliary flow in the thin mucous membrane near the border between the nose and paranasal sinuses.

\section{SURFACE EPITHELIUM}

Most of the polyp surface is covered by a ciliated pseudostratified epithelium, but a transitional and squamous epithelium is also found, especially in anterior polyps, influenced by the inhaled air currents. ${ }^{16}$

\section{Epithelial defects}

There is experimental evidence that cytotoxic proteins from eosinophil leucocytes can damage the respiratory epithelium and induce bronchial hyperreactivity in asthma. ${ }^{17}$ Epithelial defects have apparently also been described in nasal polyps, ${ }^{18}$ but when polyps are removed carefully and gentle methods are used for fixation, dehydration and cutting, the polyp epithelium appears well preserved without defects on scanning electron microscopy. ${ }^{19}$ Although gross epithelial defects do not seem to appear in carefully prepared polyp specimens, the function of the epithelium may be impaired and epithelial cell kinetics altered. ${ }^{20}$

\section{Biology of the surface epithelium}

Perturbation of the epithelium, as occurs on exposure to chemical, physical and immunological stimuli, can contribute to inflammation by release and activity of cytokines which influence the growth, differentiation, migration, and activation of inflammatory cells. ${ }^{21} 22$ Recent studies have suggested that the airway epithelium may play a more important role and influence the pathogenesis of inflammatory airway diseases. Contact between epithelial surfaces in the narrow middle meatus may partly explain why polyps are formed specifically in this location, as discussed above.
Electrolyte and water transport

The basic elements of $\mathrm{Na}^{+}$and $\mathrm{Cl}^{-}$movement in the respiratory surface epithelium may be of relevance for the understanding of nasal polyp formation. In the normal nasal mucosa there is a net absorption of $\mathrm{Na}^{+}$and very little $\mathrm{Cl}^{-}$ secretion. ${ }^{23}{ }^{24}$ In cystic fibrosis (CF), a disease often associated with polyp formation, there is both an absence of the cyclic AMP controlled $\mathrm{Cl}^{-}$channel and abnormal regulation of the $\mathrm{Na}^{+}$channel. ${ }^{23}{ }^{24}$ Increased $\mathrm{Na}^{+}$and decreased $\mathrm{Cl}^{-}$secretion in $\mathrm{CF}$ result in dehydration of mucus because of the net movement of water into the interstitial space.

Increased $\mathrm{Na}^{+}$absorption may also be secondary to chronic inflammation, which is the hallmark of nasal polyposis. Recent findings indicate that the absorption of $\mathrm{Na}^{+}$is altered, not only in CF polyps but also in non-CF polyps. ${ }^{23}{ }^{24}$ These results suggest that factors leading to the development of nasal polyposis include pathophysiological changes in the electrolyte and water transport in the surface epithelium.

GOBLET CELLS

The histopathological picture shows great variations, not only in type of epithelium but also in goblet cell density in different locations on a single polyp. The density of goblet cells is lower in anterior than in posterior polyps, and much lower than in the normal nasal mucosa. ${ }^{16}$

\section{INNERVATION}

The sensory nerves and the autonomic vasomotor and secretory nerves invariably found in normal and abnormal nasal mucosa cannot be identified within the stroma of polyps, either in the vicinity of the epithelial basement membrane or within the walls of blood vessels or glands. A few nerve fibres can be seen in the stalk of some polyps. ${ }^{25}$

It is therefore assumed that denervation of nasal polyps causes a decrease in secretory activity of the glands and induces an abnormal vascular permeability, leading to an irreversible tissue oedema. Nasal polyps develop in areas where the lining of the nasal cavity joins that of the sinuses, and these marginal zones contain thin nerve fascicles ${ }^{25}$ which may be more sensitive to damage from, for example, eosinophil derived proteins. ${ }^{26}$

While the exact cause and mechanism of the denervation of the nasal polyps are unknown, it seems likely that the complete loss of autonomic innervation is a pathogenetic factor in the formation of polyps.

SUBMUCOSAL GLANDS

The glands of nasal polyps differ markedly from normal nasal glands. ${ }^{27}$ While normal glands are small branched tubulo-alveolar glands, those in the polyps are long, tubular, and of varying shape, size, and type. The normal glands are evenly distributed over the mucous membrane, while the glands in the polyps are very unevenly distributed. Their density is more than 10 times less than in the nasal mucosa. ${ }^{27}$ 
All glands in the polyps are pathological, showing signs of cystic degeneration with stagnation of mucus within the distended tubules, ${ }^{427}$ and without the normal production of secretory component. ${ }^{28}$ All glands are apparently newly formed during the growth of the polyps, which is consistent with their lack of innervation.

BLOOD VESSELS AND EXUDATION OF PLASMA The vascularity of polyps is sparse compared with normal nasal mucosa, ${ }^{25}$ and neither venous sinusoids nor arteriovenous anastomoses are encountered. The venules of the polyps show unusual organisation with respect to their endothelial cell junctions and the basement membrane. Many cell junctions have the appearance of a web of villous processes and are incompletely sealed, while others are wide open. ${ }^{25}$ As mentioned above, the blood vessels of polyps are devoid of nerves.

The release of histamine and other inflammatory mediators (see below) may be an important factor in causing microvascular plasma exudation, which is highly characteristic of nasal polyps. The vascular exudation of plasma suggests that the lamina propria, the basement membrane, the airway epithelium, and the mucosal surface are furnished with potent plasma derived peptides and proteins, and that the mucosal macromolecular milieu in nasal polyposis is therefore dramatically different from that of the normal nasal mucosa. ${ }^{20} \mathrm{It}$ is of particular interest that the process of microvascular exudation of plasma may participate in the chronic generation of oedema fluid in nasal polyposis.

\section{Inflammation in nasal polyps}

Nasal polyposis is the ultimate form of inflammation of the upper airways which, for unknown reasons, preferably develops in subtypes of inflammatory diseases. As mentioned above, the factors which determine localisation of the disease to a few square centimetres of the airways is poorly understood.

As shown in table 1, nasal polyposis occurs very frequently in patients with intolerance to acetylsalicylic acid and in patients with allergic fungal sinusitis. These two aetiologically different diseases have an eosinophil dominated inflammation as a common feature, and the degree of tissue eosinophilia appears to be an important denominator of the recurrence rate of nasal polyps. ${ }^{5}$ In non-eosinophil dominated inflammation (cystic fibrosis, primary ciliary dyskinesia) other pathophysiological mechanisms may be of importance.

IGE, MAST CELLS, AND HISTAMINE

The number of epithelial mast cells in nasal polyps is high. ${ }^{29}$ Electron microscopic studies have shown marked and widespread mast cell degranulation in all polyps studied, and the degree of degranulation is greater than in allergic rhinitis. $^{3031}$ There is evidence that the changes may extend into the nasal mucosa of the inferior turbinate in some patients, indicating the existence of a more widespread inflammation of the airway mucosa. ${ }^{32}$ The total hista- mine content of polyps is much higher than other tissues, and large quantities of free histamine can be measured in the oedema fluid ${ }^{33}$ which fits in with the ultrastructural findings. Arachidonic acid generated mediators are also found in polyp fluid. ${ }^{34}$ Measurable levels of IgE decapeptide in polyp fluid $^{35}$ support the suggestion that a membrane event induces the degranulation of mast cells.

ADHESION MOLECULES, CYTOKINES, AND EOSINOPHILS

Immunohistochemical data strongly suggest that interactions between the adhesion molecules VLA-4 and VCAM-1 play an important role in the extravasation of eosinophils into nasal polyps. Three studies have found considerable upregulation of VCAM-1 in polyp vasculature, ${ }^{36-39}$ which supports the finding of adhesion and transmigration of eosinophils without any effect on neutrophils. Both interleukin (IL)-3 and IL-4, as well as IL-1 and tumour necrosis factor (TNF) $\alpha$ can induce VCAM-1 expression in microvascular endothelium from the polyps. All these cytokines are expressed in the polyps and, in various combinations, may have synergistic effects on VCAM-1 expression. ${ }^{36}$ Another adhesion molecule, P-selectin, also probably has a role in the initial adhesion of eosinophils to the polyp endothelium. $^{36}{ }^{39}$ Chemokines are probably involved as eosinophil attractants. Although limited information exists with regard to their possible role in vivo, reports on RANTES and eotaxin expression in nasal polyps indicate that these chemoattractants participate in the accumulation of eosinophils. ${ }^{38} 40$

Several haemopoietic and pro-inflammatory cytokines (GM-CSF, IL-6, IL-8, SCF), capable of recruiting and activating mast cells and eosinophils in particular, are upregulated in various tissue compartments (epithelium, stroma) of nasal polyps. ${ }^{41-43}$ The inflammatory cells themselves, especially eosinophils, are rich sources of many cytokines including those capable of inducing their own differentiation and activation in an autocrine fashion. Thus, nasal polyps can be looked upon as a type of self-perpetuating inflammatory process. ${ }^{44}$

The presence of large amounts of IL-5 protein in most nasal polyp specimens but in no specimens from normal control subjects or those with infectious sinusitis indicates that IL-5 has a key role in the pathophysiology of eosinophil dominated polyps. ${ }^{42}$ This is in contrast to other cytokines which have only marginal quantitative differences between polyps and other rhinosinusitis diseases. IL-5 levels are significantly higher in polyps of asthmatic subjects than in those from nonasthmatic subjects, which confirms the association between this cytokine and clinical data in patients with asthma and polyposis. ${ }^{42}$ Immunohistochemistry reveals that IL-5 may be predominantly produced by eosinophils which, as mentioned earlier, creates a possible autocrine loop in nasal polyp tissue. 
Allergy testing in patients with nasal polyposis

Since Yonge's original article on the cause of nasal polyps published in the BMF in $1907,{ }^{45}$ allergy has consistently been proposed as a cause of polyps. This widespread belief, however, is not supported in published work on allergy testing.

Settipane and Chafee ${ }^{13}$ studied 211 patients with nasal polyps referred to an allergy clinic; $55 \%$ had positive allergy skin tests. Since these patients were selected from a biased population of whom $77 \%$ had positive skin tests, the high frequency of positive allergy skin tests in nasal polyps may be misleading and may reflect the characteristics of the total population. The authors conclude that the positive allergy skin tests in nasal polyps may be a coincidence.

Wong and Dolovich ${ }^{46}$, in a series of 249 patients undergoing nasal polypectomy, reported a positive skin prick test in $66 \%$. However, using the same allergen testing panel, $74 \%$ had a positive skin test in a control group of patients undergoing non-polyp nasal surgery.

Only one study has compared allergy testing in patients with nasal polyps and a matched control group. Jamal and Marant ${ }^{47}$ found a positive RAST to inhalant allergens in $16.6 \%$ of patients with nasal polyps compared with $12.5 \%$ in an age and sex matched control group. Drake-Lee ${ }^{48}$ reported that positive skin test results are no more common than expected in patients with nasal polyps (25\%), making the presence of allergy appear to be coincidental.

The evidence therefore suggests that nasal polyps are not caused by allergy. When polyps and allergy occur together, the question is whether allergen exposure can aggravate nasal polyps and cause recurrence.

\section{Effect of allergen exposure in nasal polyposis}

It is logical to assume that allergen exposure can provoke nasal symptoms in allergic patients with coincident polyposis. However, an ingeniously designed study does not give support to this assumption. Keith and coworkers ${ }^{49}$ followed nasal symptoms and eosinophilia during the pollen season in four groups of patients: (1) allergic with polyposis, (2) non-allergic with polyposis, (3) allergic without polyposis, and (4) non-allergic without polyposis. Symptoms and nasal eosinophilia worsened during the pollen season only in allergic patients without polyposis. The authors concluded that ongoing conditions, perhaps nasal mucosal inflammation, in patients with nasal polyposis may lead to a loss of susceptibility to potential additional effects of inhaled allergen.

\section{Effect of treatment on nasal polyposis and allergic rhinitis}

$\mathrm{H}_{1}$ ANTIHISTAMINES

Hundreds of placebo-controlled studies have shown the efficacy of $\mathrm{H}_{1}$ antihistamines in the treatment of allergic rhinitis, with an excellent effect on itching and sneezing, a moderate effect on nasal hypersecretion, and a poor effect on nasal blockage. ${ }^{50}$ It is recommended in international consensus reports that $\mathrm{H}_{1}$ antihistamines are used in mild cases with occasional symptoms, while intranasal corticosteroids are recommended in severe cases with daily symptoms. ${ }^{51}$

On the other hand, there is no clinical or experimental evidence that $\mathrm{H}_{1}$ antihistamines are effective in nasal polyposis. This is remarkable, considering the extensive mast cell degranulation in nasal polyps and their extremely high content of histamine.

\section{CORTICOSTEROIDS}

Corticosteroids are the only drugs with a proven effect on symptoms and signs of nasal polyposis. ${ }^{52}{ }^{53}$ They probably relieve symptoms by downregulating the expression and production of cytokines such as IL-5 which effectively reduce the number of eosinophils. The effects of corticosteroids on these processes may be enhanced by effects on haemopoietic mechanisms arising in the bone marrow. ${ }^{54}$

Topically applied corticosteroids have been best studied in controlled clinical trials. ${ }^{52} 53$ They reduce symptoms of rhinitis, improve nasal breathing, reduce the size of polyps, and prevent, in part, their recurrence, but they have none or little effect on the sense of smell. Topical steroids can be used alone as basic long term treatment in mild cases and can be used with systemic steroids and/or surgery in severe cases.

Systemic steroids have been less well studied; they have an effect on all types of symptoms and pathology, including the sense of smell. ${ }^{55}$ This type of treatment, which can serve as "medical polypectomy", is only used for short periods because of the risk of adverse effects.

ALLERGEN SPECIFIC TREATMENT

In one of the two monographs on nasal polyps ${ }^{1}$ the editor writes: "Treatment of allergies is important in preventing recurrences in individuals with both nasal polyps and allergies. It is appropriate that all patients with nasal polyps have an allergy evaluation. Immunotherapy with allergen may be used to prevent polyp recurrence in some of these patients who have both nasal polyps and allergies."

In our opinion, however, there is no clinical or experimental evidence in support of the use of allergen specific therapy-neither allergen avoidance nor immunotherapy - in the treatment of nasal polyposis.

\section{Conclusions}

Whether allergy is a cause of nasal polyposis is a controversial issue. The fact that polyps are characterised by mast cell degranulation and high local levels of IgE and of histamine, and that there is an eosinophil dominated inflammation driven by cytokines (which are also operative in allergic inflammation), is compatible with an allergic aetiology. However, there are strong counterarguments against this. Nasal polyps do not occur with increased frequency in allergic patients and patients with 
nasal polyps do not appear to have a positive allergy skin test more often than control subjects.

We conclude that present evidence is not in favour of a causal association between allergy and nasal polyps. Allergen specific therapy has no proven efficacy in polyp patients and it is questionable whether allergy testing is indicated in these patients. Nasal polyposis, which is characterised by eosinophil dominated inflammation, is a disease of unknown aetiology.

1 Settipane GA, Lund VJ, Bernstein JM, Tos M, eds. Nasal polyps: epidemiology, pathogenesis and treatment. Providence, Rhode Island: The New England and Regional Allergy Proceedings, 1997

2 Mygind N, Lildholdt T, eds. Nasal polyposis: an inflammatory disease and its treatment. Copenhagen: Munksgaard, 1997.

3 Cody DT, Neel HB, Ferreiro JA, et al. Allergic funga sinusitis: the Mayo Clinic experience. Laryngoscope 1994; 104:1074-9.

4 Sørensen H, Mygind N, Tygstrup I, et al. Histology of nasal polyps of different etiology. Rhinology 1977;15:121-8.

5 Settipane GA. Nasal polyps: pathology, immunology and treatment. Am $\mathcal{F}$ Rhinol 1987;1:119-26.

6 van der Baan B. Epidemiology and natural history. In: Mygind N, Lildholdt T, eds. Nasal polyposis: an inflammatory disease and its treatment. Copenhagen: Munksgaard, tory disease

7 Hedman J, Kaprio J, Poussa T, et al. Prevalence of asthma, aspirin intolerance, nasal polyposis and chronic obstructive pulmonary disease in a population-based study. Int $\mathscr{f}$

8 Larsen PL, Tos M. Site of origin of nasal polyps. Transcranially removed naso-ethmoidal blocks as a screening method for nasal polyps in autopsy material. Rhinology 1995;33:185-8.

Larsen PL, Tos M. Anatomic site of origin of nasal polyps. Am f Rhinol 1996;10:211-6.

10 Annesi-Maesano I. Epidemiological evidence of the occurrence of rhinitis and sinusitis in asthmatics. Allergy 1999;54(Suppl 57):7-13.

11 Caplin I, Haynes TJ, Spahn J. Are nasal polyps an allergic phenomenon? Ann Allergy 1971;29:631-4.

12 Bunnag C, Pacharee P, Vipulakom P, et al. A study of allergic factor in nasal polyps patients. Ann Allergy 1983;50: 126-32.

13 Settipane GA, Chafee FH. Nasal polyps in asthma and rhinitis, a review of 6037 patients. 7 Allergy Clin Immunol rhinitis, a review

14 Stammberger H. Functional endoscopic sinus surgery. The Messerklinger technique. Toronto: BC Decker, 1991.

15 Stammberger H. Examination and endoscopy of the nose and paranasal sinuses. In: Mygind N, Lildholdt T, eds. Nasal polyposis: an inflammatory disease and its treatment. Copenhagen: Munksgaard, 1997: 120-36.

16 Larsen PL, Tos M. Nasal polyps. Epithelium and goblet cell density. Laryngoscope 1990;99:1274-80.

17 Garrison HA, Leonard CA, Hansson S, et al. Injurious effect of the eosinophil peroxide-hydrogen peroxide-halide system and major basic protein on human nasal epithelium in vitro. Am Rev Respir Dis 1989;140:125-31.

18 Wladislavosky-Wasserman P, Kern EB, Holley KE, et al. Epithelial damage in nasal polyps. Clin Allergy 1984;14 241-7.

19 Larsen PL, Qvortrup K, Rostgaard J, et al. Ultrastructural analyses of human nasal polyps employing an improved analyses of human nasal polyps employing an
method for immersion fixation (in preparation).

20 Greiff L, Erjefält JS, Andersson M, et al. Microvascular exudation of plasma and epithelial shedding-restitution processes as causative events in inflammatory airway diseases. In: Mygind N, Lildholdt T, eds. Nasal polyposis: an inflammatory disease and its treatment. Copenhagen: Munksgaard, 1997: 50-60

21 Devalia JL, Davies RJ. Airway epithelial cells and mediators of inflammation. Respir Med 1993;87:405-8.

22 Devalia JL, Campbell AM, Sapsford RJ, et al. Effect of nitrogen dioxide on synthesis of inflammatory cytokines expressed by human bronchial epithelial cells in vitro. $A m \mathcal{F}$ Respir Cell Mol Biol 1993;9:271-8.

23 Bernstein JM, Yankaskas JR. Increased ion transport in cultured nasal epithelial cells. Arch Otolaryngol Head Neck Surg 1994;120:993-6.

24 Bernstein JM, Yankaskas JR. Electrolyte and water transport and biophysical properties of nasal polyps. In: Mygind $\mathrm{N}$, Lildholdt T, eds. Nasal polyposis: an inflammatory disease and its treatment. Copenhagen: Munksgaard, 1997: 44-9.

25 Cauna N, Hinderer KH, Manzetti GW, et al. Fine structure of nasal polyps. Ann Otol Rhinol Laryngol 1972;81:41-8.
26 Mygind N. Nasal polyposis. Editorial. 7 Allergy Clin Immunol 1982;86:827-9.

27 Tos M, Mogensen C. Mucous glands in nasal polyps. Arch Otolaryngol 1977;103:407-13

28 Nakashima T, Hamashima Y. Loss of secretory activity in the glands of nasal polyps. Ann Otol Rhinol Laryngol 1979; 88:210-6.

29 Ruhno J, Howie K, Anderson M, et al. The increased number of epithelial mast cells in nasal polyps and adjacent turbinates is not allergy-dependent. Allergy 1990;45:370-4.

30 Drake-Lee A, Price J. Ultrastructure of mast cells in normal subjects and patients with perennial allergic rhinitis. $\mathcal{F}$ Laryngol Otol 1991;105:1006-13.

31 Drake-Lee A, Price J. Mast cell ultrastructure in the inferior turbinate and stroma of nasal polyps. F Laryngol Otol 1997; $11: 340-5$

32 Drake-Lee A. Mast cells, histamine and other mediators. In: Mygind N, Lildholdt T, eds. Nasal polyposis: an inflammatory disease and its treatment. Copenhagen: Munksgaard, 1997: 61-7.

33 Drake-Lee AB, McLauhlan P. Clinical symptoms, free histamine and IgE in nasal polyps. Int Arch Allergy Appl Immunol 1982;69:268-71.

34 Salari H, Borgeat P, Steffenrud S, et al. Immunological and non-immunological release of leukotrienes and histamine from nasal polyps. Clin Exp Immunol 1986;63:711-7.

35 Drake-Lee AB, Jones V, Lewin I, et al. Levels of substance P and IgE decapeptide in nasal polyp fluid and matching sera: a preliminary study. $\mathcal{F}$ Laryngol Otol 1996;110:225-7.

36 Jahnsen FL, Haraldsen G Haye R, et al. Adhesion molecules and recruitment of eosinophils. In: Mygind N, Lildholdt T, eds. Nasal polyposis: an inflammatory disease and its treatment. Copenhagen: Munksgaard, 1997: 88-97.

37 Jahnsen FL, Haraldsen G, Aanesen JP, et al. Eosinophil infiltration is related to increased expression of vascular cell adhesion molecule-1 in nasal polyps. Am $\mathcal{F}$ Respir Cell Mol Biol 1995;12:624-32.

38 Beck L, Stellato C, Beall D, et al. Detection of chemokine RANTES and endothelial adhesion molecules in nasal polyps. F Allergy Clin Immunol 1996;98:766-80.

39 Tingsgaard PK, Bock T, Larsen PL, et al. Topical budesonide treatment reduces endothelial expression of intercellular adhesion molecules (VCAM-1 and P-selectin) and eosinophil infiltration in nasal polyps. Acta Otolaryngol (Stockh) 1999;119:362-8.

40 Hamilos DL, Leung DYM, Huston DP, et al. GM-SCF, IL-5 and RANTES immunoreactivity and mRNA expression in chronic hyperplastic sinusitis with nasal polyposis. Clin Exp Allergy 1998;28:1145-52.

41 Jordana $M$, Dolovich J, Ohno I, et al. Nasal polyposis: a model for chronic inflammation. In: Busse WW, Holgate ST, eds. Asthma and rhinitis. Boston: Blackwell, 1995:15664 .

42 Bachert C. Comparison between polyp tissue, diseased sinus mucosa and normal nasal tissue. In: Mygind N, Lildholdt T, eds. Nasal polyposis: an inflammatory disease and its treatment. Copenhagen: Munksgaard, 1997: 98-104.

43 Bachert C, Wagenman M, Hauser U, et al. IL-5 synthesis is upregulated in human nasal polyp tissue. F Allergy Clin Immunol 1997;99:837-42.

44 Denburg J. Nasal polyposis: cytokines and inflammatory cells. In: Mygind N, Lildholdt T, eds. Nasal polyposis: an inflammatory disease and its treatment. Copenhagen: Munksgaard, 1997: 78-87.

45 Younge ES. The determining causes of nasal polyps. BMF 1907;2:964-9.

46 Wong D, Dolovich J. Blood eosinophilia and nasal polyps. Am F Rhinol 1992;6:195-8.

47 Jamal A, Marant AGD. Atopy and nasal polyposis. F Laryngol Otol 1987;101:355-8.

48 Drake-Lee AS. Nasal polyps. In: Mackay IS, ed. Rhinitis: mechanisms and management. London: Royal Scociety of Medicine, 1989: 141-52.

49 Keith PK, Conway M, Evans S, et al. Nasal polyps: effects of seasonal allergen exposure. F Allergy Clin Immunol 1994;93: 567-74.

50 Simons FER. Antihistamines. In: Naclerio RM, Durham SR, Mygind N, eds. Rhinitis. Mechanisms and management. New York: Marcel Decker, 1999: 267-90

51 Lund V, Aaronson D, Bousquet J, et al. International consensus report on the diagnosis and management of rhinitis. Allergy 1994;49(Suppl 19):1-34

52 Mygind N, Lund V. Topical corticosteroid therapy of rhinitis. Clin Immunother 1996;5:122-36.

53 Lildholdt T, Mygind N. Effect of corticosteroids on nasal polyps. In: Mygind N, Lildholdt T, eds. Nasal polyposis: an inflammatory disease and its treatment. Copenhagen: Munksgaard, 1997: 160-9.

54 Kanai N, Denburg J, Jordana $M$, et al. Nasal polyp inflammation. Effect of topical nasal steroid. Am f Respir Crit Care Med 1994;150:1094-100.

55 Lildholdt T, Fogstrup J, Gammelgaard N, et al. Surgical versus medical treatment of nasal polyps. Acta Otolaryngol (Stockh) 1988;105:140-3. 